\title{
Surgical Management of Superior Labral Tears in Athletes: Focus on Biceps Tenodesis
}

\author{
Garrett V Christensen \\ Karch M Smith \\ Jun Kawakami \\ Peter N Chalmers
}

Department of Orthopaedic Surgery, University of Utah Health, Salt Lake City, UT, USA
Correspondence: Peter N Chalmers

Department of Orthopaedic Surgery, 590

Wakara Way, Salt Lake City, UT, 84I05

Tel +I 5038030643

Fax + I 3147472599

Email Peter.Chalmers@hsc.utah.edu

\begin{abstract}
Superior labrum anterior-posterior (SLAP) lesions are common in overhead athletes. Though some patients have asymptomatic lesions, many tears cause pain and diminished athletic performance. Accurate diagnosis of SLAP lesions can be challenging as the sensitivity and specificity of both the physical exam and advanced imaging is questionable. Management is also difficult, as treatment can be life-altering or careerending for many athletes. If first-line nonoperative treatment fails, surgical options may be considered. The optimal surgical management of SLAP lesions in athletes is debated. Historically, return to play (RTP) rates among athletes who have undergone arthroscopic SLAP repair have been unsatisfactory, prompting clinicians to seek alternate surgical options. Biceps tenodesis (BT) has been postulated to eliminate biceps tendon-related pain in the shoulder and is increasingly used as a primary procedure for SLAP lesions. The purpose of this text is to review the current literature on the surgical management of SLAP lesions in athletes with an emphasis on the role of BT.
\end{abstract}

Keywords: SLAP tear, SLAP lesion, superior labrum anterior-posterior, biceps-labral complex, throwing athlete, overhead athlete

\section{Introduction}

The superior aspect of the glenoid labrum combines with the long head of the biceps brachii tendon to form the biceps-labral complex. Injuries to this complex are termed Superior Labrum Anterior-Posterior (SLAP) lesions and were initially described by Andrews et al in the mid-1980s. ${ }^{1}$ Athletes, particularly those using repetitive overhead movements, are prone to developing lesions of the superior labrum with or without biceps tendinosis. ${ }^{2,3}$ Since the pathology's description, accurate diagnosis has been problematic, and treatments have varied. ${ }^{4-6}$ Management is controversial, especially in the young athlete who wishes to return to his/her preinjury level of play.

Nonoperative treatment, including physical therapy and rest from sport, is firstline. If nonoperative management fails, surgery may be considered. The optimal surgical procedure for type II SLAP repairs in athletes remains controversial. Studies evaluating isolated SLAP repair with suture anchors often report disappointing return to play (RTP) rates for overhead athletes. ${ }^{7,8}$ Some argue that procedures such as biceps tenodesis (BT) may help relieve pain, and, as such, these procedures have become much more common in young athletes over the last decade. $^{5,9,10}$ It has been increasingly recognized that BT likely does not alter shoulder biomechanics or prevent a return to full athletic performance postoperatively. $^{11}$ 


\section{Epidemiology}

Since being described and classified, the diagnosis of SLAP lesions has increased drastically, as has the surgical treatment of such, especially in the overhead athlete. ${ }^{6,12}$ Lesniak et al found that in their Magnetic Resonance Imaging (MRI) study of the throwing arm of 21 professional baseball pitchers, nearly $50 \%$ had evidence of a SLAP lesion. Yet, every pitcher in this series was asymptomatic. ${ }^{13}$ While the literature discussing injuries to overhead athletes is dominated by baseball studies, SLAP lesions are also prevalent in other overhead sports -tennis, volleyball, and gymnastics, to name a few. ${ }^{14-16}$

The exact incidence of SLAP lesions is unknown; however, several studies have attempted to quantify the diagnosis. Dougherty et al queried private insurance claims in the United States and found that the diagnosis of SLAP lesions increased from 28 per 100,000 in 2003 to 142 per 100,000 in 2013. ${ }^{12}$ Weber et al queried the American Board of Orthopedic Surgery Part II database and found that in 2008, 9.4\% of all applicants' shoulder cases were SLAP repairs. ${ }^{6}$ Jo et al reported on isolated SLAP repairs in Korea and found that in the last ten years, the SLAP repair incidence rate was approximately 5-8 per $100,000 .{ }^{17}$ While Jo et al do not report on the number of diagnoses, we can presume that the diagnosis of SLAP lesions is much higher than the number of SLAP repairs performed. The studies above do not precisely disclose the incidence of SLAP lesions in athletes. However, they demonstrate that SLAP lesions are a common problem that any clinician involved in treating athletes should be familiar with.

\section{Classification}

SLAP lesions were first classified by Snyder et al in $1990 .^{18}$ Type I lesions account for approximately $11 \%$ of SLAP tears and are characterized by both biceps and labral fraying, with an intact anchor. Type II tears account for approximately $41 \%$ of tears and are characterized by labral fraying with a detached biceps tendon anchor (Figure 1). Type III lesions account for $33 \%$ of tears and are characterized by a bucket-handle type tear of the labrum with an intact biceps tendon anchor. Finally, type IV tears account for approximately $15 \%$ of tears. They are characterized by a bucket-handle type tear of the superior labrum with a biceps tendon separated from the scapula, but still attached to the bucket-handle portion of the superior labrum. ${ }^{18}$

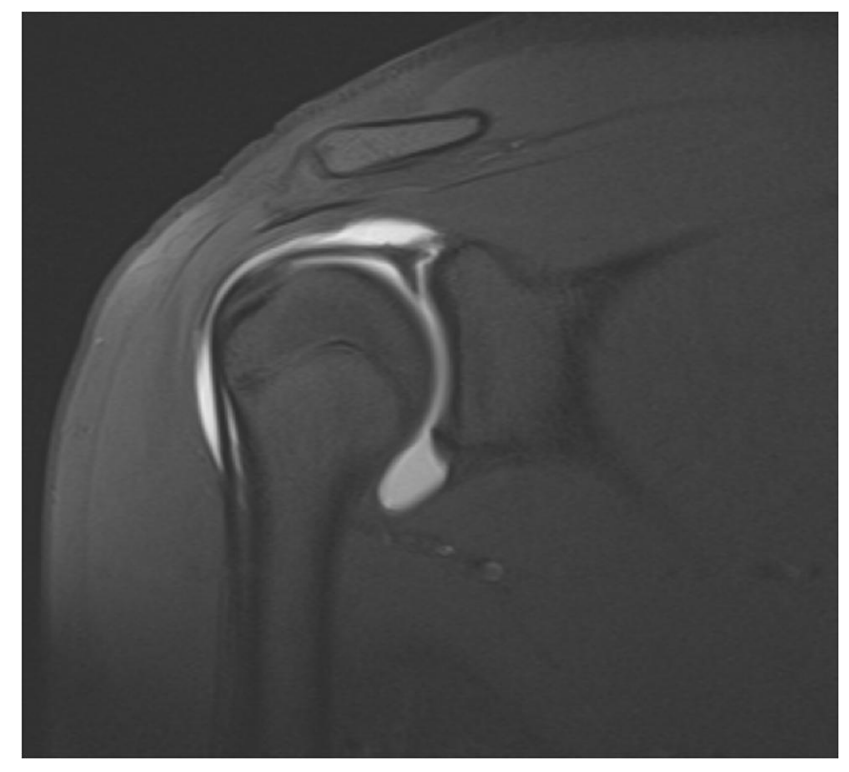

Figure I A coronal slice of a magnetic resonance arthrogram showing a type II SLAP lesion in a female college gymnast.

As type II lesions are significantly more common in athletes than types I, III, and IV, a SLAP lesion in this text will indicate a type II lesion unless otherwise specified. There is good agreement that type III and IV lesions should be treated with BT and type I lesions, are generally treated with surgical debridement in the absence of other symptoms specific to the biceps.

Since the original classification was published, there have been attempts to subclassify SLAP tears to be more descriptive and granular. ${ }^{19,20}$ Still, the original Snyder classification is primarily used in the literature because of its simplicity and will be used throughout this text.

\section{Pathogenesis}

Several mechanisms have been proposed for the pathogenesis of SLAP lesions. In the 1980s and 1990s, it was thought that SLAP lesions resulted from a traction injury to the biceps tendon predominantly as the biceps aided in decelerating the arm late in the throwing motion. ${ }^{1}$ Later, Burkhart et al theorized that the pathogenesis was a "peel back" injury mechanism primarily due to adaptive anterior laxity of the shoulder capsule with posterior capsular tightening. Lax anterior tissue allows for the anterior translation of the humeral head during the throwing motion, which impinges the articular portion of the rotator cuff against the posterosuperior glenoid labrum. Chronically, this pushes the biceps-labral complex medially, detaching it from the glenoid rim. ${ }^{21,22}$ These pathogenic mechanisms 
have been studied in biomechanical and cadaver models. Many studies show that the biceps-labral complex is under maximal tension during the late cocking phase of throwing, while the arm is abducted and maximally externally rotated. $^{23-25}$

\section{Diagnosis \\ History}

The diagnosis of a SLAP lesion begins with a thorough history. Athletes commonly note vague, deep shoulder pain, which may be anterior or posterior, acute or chronic, traumatic or atraumatic. The pain generally worsens with overhead movements. Some athletes notice mechanical symptoms such as catching, clicking, locking, or popping in the shoulder. Athletes often complain of decreased performance in their sport-particularly if they are overhead athletes. Clinicians should ask about subjective instability, as rotator cuff and labral injuries may predispose to instability.

\section{Physical Exam}

The physical exam must be detailed, and clinicians should remember that no single physical exam maneuver is diagnostic. Bilateral shoulders should be inspected for any asymmetry, scapular abnormalities, muscle atrophy, or joint effusions. Palpation should focus on the tenderness of the bicipital groove, the subpectoral region of the humerus, and even pain in the biceps brachii muscle belly. The glenohumeral joint line, coracoid process, and the acromioclavicular joint line should be palpated for tenderness.

Active and passive range of motion of the glenohumeral and scapulothoracic joints should be evaluated. Range of motion exam may show decreased internal rotation and increased external rotation of the dominant arm compared to the contralateral extremity, a common finding in throwing athletes. ${ }^{26}$ Strength in the periscapular and brachial musculature should be tested. Neurovascular status should be documented, with particular attention to the supraspinatus and infraspinatus.

Provocative tests should be performed, such as the O'Brien active compression test. The active compression test has been shown to have a sensitivity of $47-100 \%{ }^{27-34}$ The test is performed when a standing patient flexes their arm to $90^{\circ}$ with an extended elbow. The arm is adducted $10^{\circ}-15^{\circ}$, so the arm is directly in front of the patient's body. The thumb should then be directed toward the floor, internally rotating the arm. The clinician then applies a downward force to the arm. Next, the patient supinates the hand, externally rotating the arm, and leaves the arm in the same adducted position when the clinician again applies a downward force to the arm. The test is considered positive when the first maneuver causes shoulder pain, while the second maneuver alleviates it. $^{29}$

Another useful provocative test is the dynamic labral shear test. This test is performed with the clinician behind the patient, both standing. The clinician holds the patient's wrist with one hand and with the other hand applies an anteriorly directed force on the proximal humerus. The patient completely relaxes their extremity as the clinician abducts the patient's arm to maximal abduction in the plane of the body. A positive test is one in which there is a click posteriorly, or the patient has pain when abducted beyond $90^{\circ} .{ }^{35,36}$

Other maneuvers include Jobe's test, the biceps load test, Speed's test, and Yergason's test, though each of these tests has been difficult to validate in isolation. ${ }^{29,37,38}$ The senior author has primarily used the superior shear test for diagnosis. In this test, proximal pressure is placed on the adducted and slightly flexed arm, which is then brought into abduction. If a clunk is appreciated, this often denotes a SLAP lesion. This test is essentially a variant of the Jerk test for posterior instability. While this test has not been studied in terms of its sensitivity and specificity, it has reliably been positive in patients with SLAP lesions, and is another tool a surgeon can use in making a diagnosis.

\section{Imaging}

If there is strong reason to believe a patient may have a SLAP lesion, a clinician may elect to order anteroposterior, axillary, and Grashey radiographs of the shoulder, but these are often normal. A more useful test is an MRI of the shoulder. However, MRI scans should be considered with caution, as Sheridan et al report that MRI has only moderate sensitivity and specificity in diagnosing SLAP lesions, and Clark et al found that a series of physical exam maneuvers may be even more diagnostically accurate than MRI in diagnosing SLAP lesions (Figure 2). ${ }^{37,38,39}$ Systematic reviews by Symanski et al and Arirachakaran et al report composite sensitivity of MRI and Magnetic Resonance Arthrography (MRA) to be 63.$0-76.0 \%$ and $80.4-87 \%$, respectively. The same studies showed the specificity of MRI and MRA to be $87.0-87.2 \%$ and $90.7-92 \%$, respectively. ${ }^{40,41}$

Diagnosis is complicated by variants of normal anatomy that can appear pathologic on advanced imaging, 


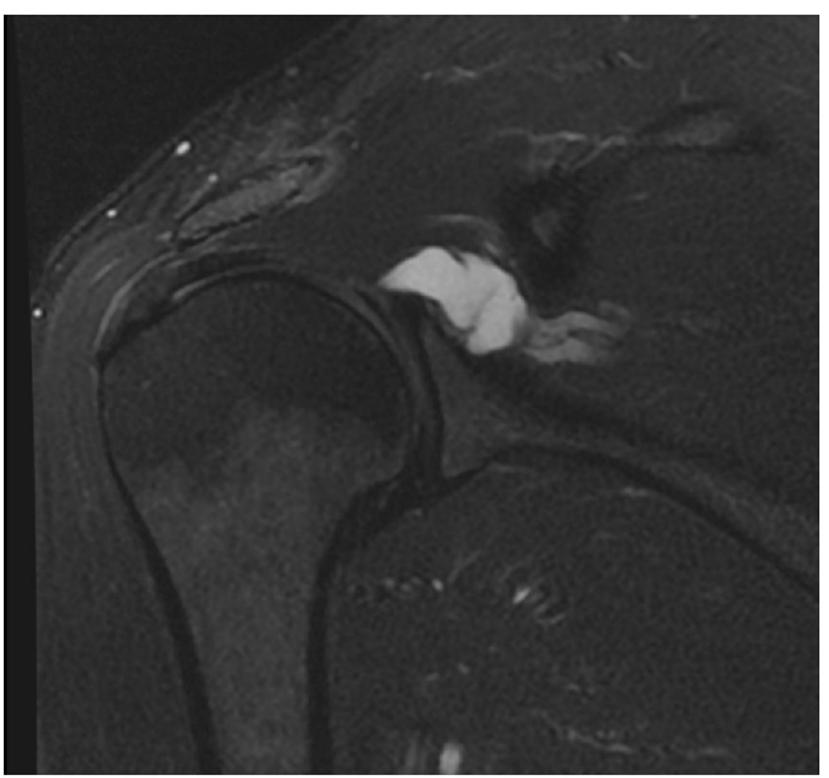

Figure 2 A coronal slice of a magnetic resonance arthrogram demonstrating a paralabral cyst in a 38-year-old male.

such as a sublabral foramen, sublabral recess, or absent anterosuperior labrum with cord-like middle glenohumeral ligament, also known as a Buford complex. ${ }^{42}$ Kanatli et al report that in their series of over 700 shoulders evaluated by arthroscopy, these combined variants were apparent in $14.2 \%$ of shoulders. ${ }^{42}$ Rao et al published similar findings in their series of nearly 550 patients, finding that $13.4 \%$ of shoulders showed variant superior labral anatomy. ${ }^{43}$ Thus, the appearance of the MRI must always be interpreted in light of the patient's symptoms and exam.

\section{Management \\ Nonoperative}

A trial of nonoperative management should focus on strengthening the shoulder girdle musculature, improving scapular dynamics, and rest from aggravating movements under a professional's supervision. Intraarticular glenohumeral corticosteroid injections may assist in the diagnosis. ${ }^{44,45}$ They can also help with pain in the short term; thereby, facilitating physical therapy in patients unable to participate in therapy due to pain.

In their prospective study on the nonoperative management of SLAP lesions, Shin et al found that, of 46 patients, 39 (85\%) had improvement in their American Shoulder and Elbow Surgeons (ASES) scores, Visual Analog Scale (VAS) for pain, and Constant scores at final follow-up, though these were only recreational athletes. ${ }^{45}$ In their case series, Edwards et al also showed improvement in

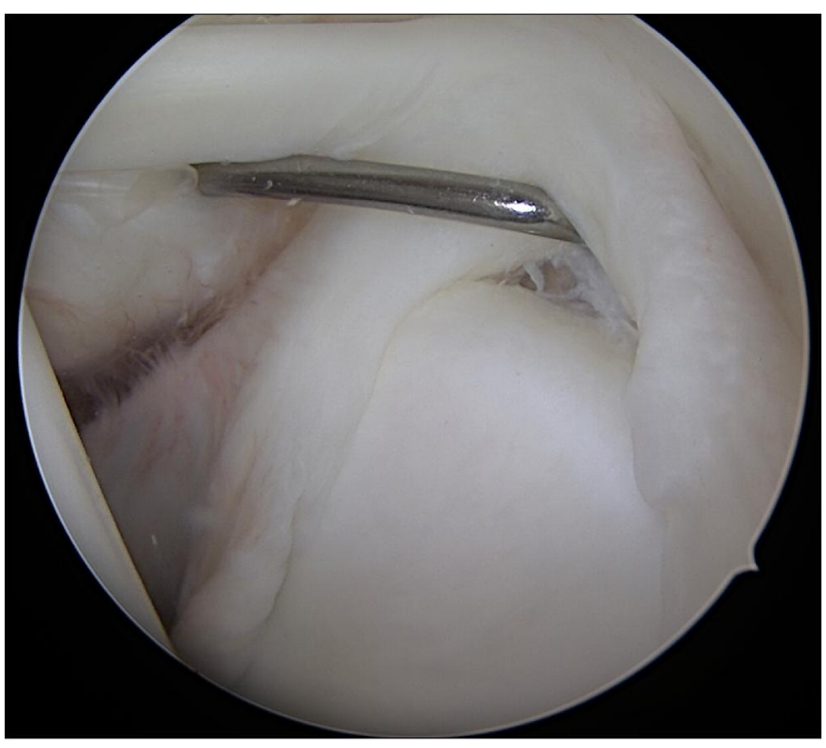

Figure 3 An arthroscopic image of a type II SLAP lesion.

ASES scores from 58.5 to 84.7, and VAS pain scores improved from 4.5 to 2.1 with nonoperative treatment, at an average follow-up of 3.1 years. In this analysis, however, only $66 \%$ of overhead athletes were able to return to preinjury level of play. ${ }^{46}$ Fedoriw et al found that the RTP rate for professional baseball pitchers with SLAP lesions treated nonoperatively was $40 \%$, and only $22 \%$ returned to prior level of performance. ${ }^{47}$

The senior author prefers at least 6-12 weeks of physical therapy, which should include active range of motion focusing on stretching the pectoralis major and posterior capsule. Therapy should also focus on strengthening the rotator cuff as well as the scapular stabilizers; namely the rhomboids, trapezius, levator scapulae, and serratus anterior. The patient also must participate in a home exercise program. Typically, the shoulder should have full painless strength and motion before a return-to-play program can be initiated. For overhead throwers, there is typically another six weeks of an interval throwing progression program once strengthening is complete.

\section{Operative}

The optimal operative management of type II SLAP lesions in athletes is debated (Figure 3). Beginning in the 1980s, SLAP lesions in both athletes and non-athletes were largely treated with arthroscopic SLAP repair (Figure 4). ${ }^{1}$ Arthroscopic SLAP repair among the general, non-overhead athlete population has been quite successful, with good-to-excellent results in up to $94 \%$ of patients. ${ }^{7,8,48-50}$ Still, SLAP repairs in overhead athletes 


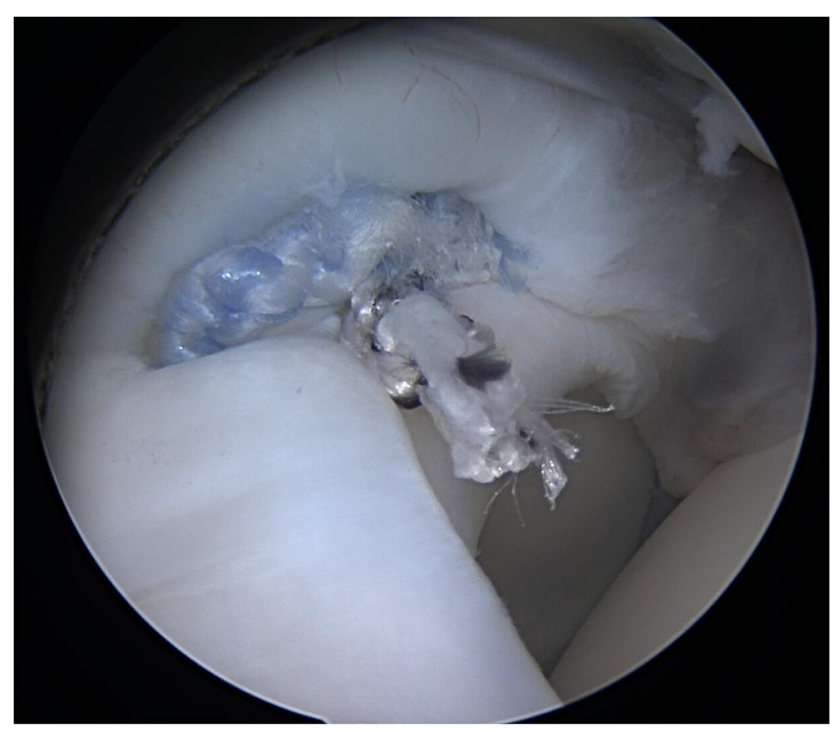

Figure 4 An arthroscopic image of a completed SLAP repair with suture anchors.

have shown mixed, if not poor, results. Gorantla et al, in their 2010 systematic review, found RTP rates for baseball players to be $22 \%-64 \%{ }^{7}$ Sayde et al performed a systematic review in 2012 and found similar results, with a composite $63 \%$ RTP for overhead athletes. ${ }^{8}$

Pain of the biceps tendon could explain why RTP rates remain low status-post arthroscopic SLAP repair. Some postulate that BT may alleviate the biceps tendon-related pain and increase RTP rates for athletes. Alternatively, it may be that the healing potential of the superior labrum is poor due to the degenerative nature of the condition, the poor vascularity of this region, and the traction of the biceps tendon distracting the repair site. BT overcomes the issue of failure of healing of the superior labrum by completely bypassing this area.

The long head of the biceps tendon has unknown significance concerning kinematics of the throwing motion. Some claim that the biceps tendon's primary role is as a static stabilizer of the glenohumeral joint. ${ }^{51,52}$ Others theorize the biceps tendon as an important depressor of the humeral head - as it crosses the glenohumeral joint superior to the humeral head, and thus, has a force vector that pushes the humerus inferiorly. ${ }^{53}$

However, one combined motion analysis and electromyographic study demonstrated that BT better restored both neuromuscular function and the pitching motion than arthroscopic SLAP repair. ${ }^{11}$ Another study by Giphart et al evaluated translation of the humeral head on the glenoid during simulated throwing positions. They compared shoulders status-post BT versus healthy controls. They found that the tenodesed shoulder had only minimal changes in humeral head translation, with average differences less than 1 millimeter. This is thought to be a clinically insignificant difference and this study suggests that the biceps tendon may not play a large role in the kinematics of the throwing motion. ${ }^{54}$ Thus, regarding the biomechanics of the throwing motion postoperatively, BT may generate more physiologic kinematics than SLAP repair, despite what was once believed.

Several studies have examined RTP rates status-post BT in athletes, though most are small case series (Table 1). Chalmers et al reported that, of Major League Baseball players who underwent isolated BT from 2010-2013, RTP was $44 \%$; however, there was no sub-analysis of pitchers

Table I Return-to-Play Outcomes Status-Post Biceps Tenodesis

\begin{tabular}{|l|c|c|c|}
\hline Author (Year) & $\begin{array}{c}\text { Percent Return-to-Play } \\
\text { Overall }\end{array}$ & $\begin{array}{c}\text { Percent Return to Preinjury Level of } \\
\text { Play }\end{array}$ & Notes \\
\hline Chalmers $(2018)^{55}$ & $44 \%$ & $44 \%$ & All professional baseball players \\
\hline Griffin $(2019)^{56}$ & $73 \%$ & $56 \%$ & $\begin{array}{c}\text { RTP for overhead athletes was } \\
80 \%\end{array}$ \\
\hline $\begin{array}{l}\text { Pogorzelski }(2018)^{57} \\
\text { Frantz }(2020)^{58}\end{array}$ & $100 \%$ & $73 \%$ & Systematic review \\
\hline Dunne $(2020)^{59}$ & $70 \%$ & & Systematic review \\
\hline $\begin{array}{l}\text { Abdul-Rassoul } \\
(2019)^{60}\end{array}$ & $83 \%$ & $78.6 \%$ & \\
\hline Chalmers $(2016)^{62}$ & $84.5 \%$ & $75 \%$ & \\
\hline
\end{tabular}


vs position athletes. ${ }^{55}$ Griffin et al followed athletes for an average of 39 months status-post BT for SLAP tear and found RTP rate to be $73 \%$. An important note, though, is that of all athletes in the study, only $56 \%$ returned to preinjury level of play. A subgroup analysis found that $77 \%$ of overhead athletes were able to return to preinjury level of play. The authors also noted no significant difference in return to preinjury level of play in overhead vs non-overhead athletes. ${ }^{56}$ In their small case series consisting largely of recreational mixed-sport athletes under 45 years of age with isolated type II SLAP tears, Pogorzelski et al found RTP was $100 \%$ at an average 3.4 years followup status-post BT for SLAP tear. However, $73 \%$ of patients indicated that they returned to a preinjury level of play. Subgroup analysis of overhead athletes showed an $80 \%$ RTP of similar level postoperatively. ${ }^{57}$

In 2020, Frantz et al performed a systematic review of the literature on BT for SLAP tears in overhead athletes. They found that athletes' average postoperative ASES score was 81.7-97, VAS for pain was 0.8-1.5, and athlete satisfaction was $80-87 \%$. Importantly, they found the composite RTP rate for overhead athletes was $70 \%$. They discovered that recreational and collegiate athletes had a higher RTP rate $(69 \%$ and $80 \%$, respectively) than professional athletes $(60 \%) .{ }^{58}$ The review only included 99 total athletes - thus, the literature is still scarce on the subject.

In comparing arthroscopic SLAP repair versus BT for type II SLAP lesions in younger patients, Dunne et al performed a retrospective cohort study of 53 patients aged 15-40 years (33 SLAP repair; $20 \mathrm{BT}$ ). Of the patients, 39 (74\%) were male and 51 (96\%) played sports at least recreationally. 22 (42\%) played sports competitively, and 30 (57\%) were overhead athletes. The authors found no difference in ASES, VAS for pain, or satisfaction scores between the groups at two-year follow-up. They found the RTP rates to be similar (50\% SLAP repair; $63 \%$ tenodesis). ${ }^{59}$ Abdul-Rassoul et al performed a systematic review in 2019 comparing 1) arthroscopic SLAP repair versus 2) SLAP repair with concomitant rotator cuff debridement versus 3) BT. The patients in the systematic review were both overhead and nonoverhead athletes in mixed sports, from recreational to professional. They found that composite RTP rates among all athletes were $79.5 \%$ for isolated SLAP repair, $76.6 \%$ for SLAP repair with rotator cuff debridement, and $84.5 \%$ for BT. RTP at a preinjury level was $63.6 \%$ for isolated SLAP repair, $66.7 \%$ for SLAP repair with rotator cuff debridement, and $78.6 \%$ for BT. ${ }^{60} \mathrm{Li}$ et al analyzed peer-reviewed studies with published outcomes of BT versus arthroscopic SLAP repair. They found no significant difference in postoperative ASES or VAS scores between the groups, but the BT cohort had significantly better RTP rates comparatively. ${ }^{61}$

One theory is that SLAP repair with concomitant BT may alleviate biceps-related pain and stabilize the superior glenoid labrum. Chalmers et al performed a comparative study of 1) BT versus 2) isolated arthroscopic SLAP repair versus 3) combined SLAP repair and BT. The study cohort consisted of both athletes and non-athletes with SLAP lesions. Of the 46 athletes in the study, $32(70 \%)$ were overhead athletes, but the authors did not report on sport or level of play. They found that RTP at a preinjury level was $75 \%$ for BT, $64 \%$ for SLAP repair, and $64 \%$ for combined SLAP repair and BT, not a statistically significant difference. However, the combined SLAP repair and BT group did have significantly worse postoperative VAS pain and ASES scores than the other two groups. ${ }^{62}$ However, this was a retrospective, nonrandomized study and this result may suggest that the patients for whom the surgeon felt a combined labral repair and BT had worse pathology than the patients for whom either an isolated SLAP repair or BT was felt to be sufficient.

In terms of relative indications, it is the senior author's belief that when there are clear signs of biceps tendonitis, such as tenderness to palpation in the bicipital groove, split tears of the biceps on MRI, or a temporary response to a guided corticosteroid injection, BT is indicated. Relative indications for SLAP repair over BT include evidence of a paralabral cyst, SLAP tears in association with repairable anterior or posterior labral tears, and young athletes with a history of discrete trauma within the past three months and subsequent mechanical symptoms. In non-athletes with complaints of both shoulder pain and shoulder instability, combined SLAP repair and BT is considered, but this is uncommon. For all others with type II SLAP tears, superior labral debridement and BT is indicated.

\section{Surgical Technique}

Suprapectoral and subpectoral BT techniques have been compared and reported. ${ }^{63-75}$ This text will describe the surgical technique for open subpectoral BT, which the senior author's preference. After the administration of general anesthesia, the patient is placed in the beach chair position. Diagnostic arthroscopy and tenotomy of the long head of the biceps tendon is performed using standard arthroscopic 
portals. The author prefers to perform the tenotomy using a radiofrequency device to create a burned end for the tendon, which allows the surgeon to confirm that the correct structure was retrieved later in the procedure from the subpectoral incision. It is also an efficient method of cutting the tendon. The tenotomy is confirmed as the tendon retracts distally into the bicipital groove. Occasionally, the tendon can be "milked" farther down the groove with gentle massage of the lateral head of the biceps muscle if the tendon does not retract and is in the way in the joint. After the tenotomy, any residual fraying within the superior labrum is debrided to create a stable base.

Next, an open subpectoral BT is performed. The inferior edge of the pectoralis major is palpated. An approximately $2-3 \mathrm{~cm}$ longitudinal incision is made just lateral to the axillary fold beginning approximately $1 \mathrm{~cm}$ superior to the palpable pectoralis major tendon. Caution should be taken to avoid the neurovascular structures medially. After dissection through the subcutaneous tissues, the pectoralis fascia is identified. The fascia is entered at the inferior edge and dissected laterally and superiorly to the anterior humeral cortex. The long head of the biceps tendon is located within the bicipital groove. Ensuring that the medial neurovascular structures are protected, the tendon is retrieved from the wound. Using a \#2 suture, a whip stitch is passed through the biceps tendon ending at the musculotendinous junction. The remaining proximal tendon is excised (Figure 5).

The senior author uses an endocortical button for fixation of the tendon. It should be noted that suture anchor

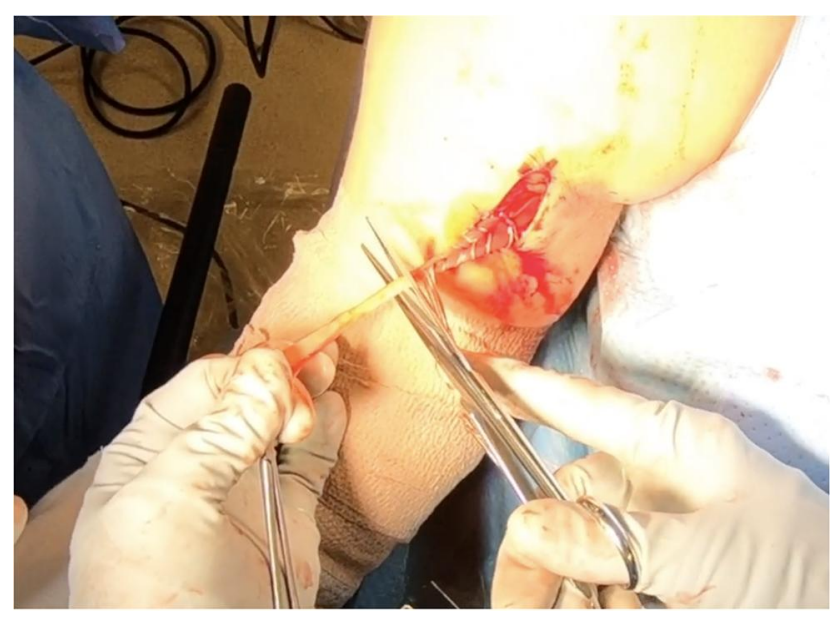

Figure 5 In this image of a biceps tenodesis in a right shoulder, the biceps tendon has been retrieved through the open incision lateral to the axillary fold. The image shows a whip stitch through the musculotendinous junction and the surgeon demonstrating the location to excise the proximal tendon with scissors. fixation, fixation over a drill hole as in the keyhole technique, and interference screw fixation have all been successfully employed and all are acceptable. While the method of fixation likely does not alter the outcome, fixating the proximal musculotendinous junction at the proper position relative to the humerus is critically important for the outcome. Placing the junction too proximally can result in significant continued pain, while placing the junction too distally can result in cramping. Anatomically, the proximal musculotendinous junction should be positioned one centimeter above the inferior border of the pectoralis major.

The senior author prefers an open subpectoral tenodesis technique because it affords the surgeon with this landmark within the muscle-tendon unit to ensure that tensioning will be accurate, while suprapectoral arthroscopic techniques do not provide any landmarks within the tendon and thus the tension can easily be incorrect. To visualize this location, a small Hohmann retractor placed through the pectoralis major tendon over the lateral humerus can help to retract the tendon superolaterally. Once this location is identified, the periosteum is removed from the bicipital groove. The fixation can then be placed in this location. For the button technique, a $3.2 \mathrm{~mm}$ hole is drilled unicortically and the button is placed endosteally within this hole, and flipped. Using the button as a pulley, the biceps tendon is then reduced to the groove and the two sutures can then be tied together. The strength of the tenodesis is confirmed and the reduction of the lengthtension relationship is verified as anatomic. The wound is irrigated and closed in a standard fashion. A sling is placed postoperatively.

\section{Postoperative Rehabilitation}

Patients should begin immediate range of motion postoperatively, which includes scapular range of motion. Progression should be from passive to active-assisted to active motion as tolerated. All cross-body adduction and rotational motions in flexion or abduction should be avoided until patients have achieved near-normal shoulder flexion and external rotation. Resisted elbow flexion and forearm supination should be avoided for the first six weeks to avoid stressing the BT.

Strengthening can begin once pain has subsided and the patient is advancing toward symmetric active range of motion, which is generally around four weeks postoperatively. Strengthening should focus on the scapular stabilizers, rotator cuff, and deltoid. Positions of impingement 
should be avoided. Return to sport, including throwing, can occur around three months postoperatively, while pitching from the mound, and collision sports are generally safe around 4.5 month postoperatively.

\section{Complications}

BT is not without complications. It has been reported that arthroscopic suprapectoral versus open subpectoral tenodesis techniques have unique complications. ${ }^{76}$ This text will focus primarily on open subpectoral tenodesis complications. In a 2020 systematic review and meta-analysis by Deng et al, it was noted that patients had residual pain in $4.7 \%$ of cases after open tenodesis. That was similar to the arthroscopic tenodesis cohort, which had residual pain in $5.7 \%$ of cases. ${ }^{76}$

Other relatively uncommon complications include postoperative stiffness, wound erythema, and nerverelated injuries. Deng et al found postoperative stiffness to be present in only $2.7 \%$ of open tenodesis cases. The authors noted that three of the 295 (1\%) open cases developed wound erythema concerning for surgical site infection. Two of the $295(0.7 \%)$ open cases were reported to have nerve-related injuries, though one was determined to be due to an interscalene block perioperatively. ${ }^{76}$ Surgeons should pay close attention to sterile technique and be gentle with traction during tenodesis procedures, as branches of the brachial plexus, particularly the musculocutaneous nerve, may traverse near the tenodesis site. Neurovascular complications and infection risk are the most commonly cited reasons for an arthroscopic approach to the BT, however, the senior author has performed over 500 BT procedures using the technique described above with no neurovascular complications or need to return to the operating room for irrigation and debridement.

\section{Discussion}

Type II SLAP lesions are difficult to diagnose and manage - particularly in overhead athletes. It is difficult to draw conclusions from the literature, as most articles are small retrospective cohort studies. BT appears to be a viable option for the primary treatment of SLAP lesions if nonoperative treatment fails (Table 2). BT has high levels of patient satisfaction, and RTP at a preinjury level in the $44-85 \%$ range, with recreational and college-level athletes having higher RTP rates than professional athletes. ${ }^{55,58}$ Rates of BT as a primary procedure for SLAP lesions are increasing, with a proportional decrease in arthroscopic SLAP repairs. ${ }^{5,45}$ To our knowledge, there have been no reports of long-term deleterious effects of removing the
Table 2 Pearls and Pitfalls of Biceps Tenodesis in Athletes

\begin{tabular}{|l|c|}
\hline Pearls & \multicolumn{1}{|c|}{ Pitfalls } \\
\hline $\begin{array}{l}\text { Exhaust all nonoperative } \\
\text { therapies before attempting } \\
\text { surgical management of a SLAP } \\
\text { lesion in athletes. }\end{array}$ & $\begin{array}{c}\text { Incorrect tension of the biceps } \\
\text { after tenodesis can lead to } \\
\text { cramping, or continued pain. Use } \\
\text { reproducible landmarks to } \\
\text { anchor the biceps into the } \\
\text { humerus. }\end{array}$ \\
\hline $\begin{array}{l}\text { Sensitivity and specificity of the } \\
\text { physical exam in diagnosing } \\
\text { a SLAP lesion increases with } \\
\text { several provocative tests. The } \\
\text { senior author prefers the } \\
\text { dynamic labral shear test, the } \\
\text { O'Brien active compression test, } \\
\text { and the superior shear test. }\end{array}$ & $\begin{array}{l}\text { A diagnosis of a symptomatic } \\
\text { SLAP lesion cannot be made on } \\
\text { imaging alone and it requires an } \\
\text { appropriate history and physical } \\
\text { examination. }\end{array}$ \\
\hline $\begin{array}{l}\text { Be mindful of normal variants in } \\
\text { labral anatomy, as approximately } \\
\text { I } 4 \% \text { of patients may have } \\
\text { a sublabral foramen, sublabral } \\
\text { recess, or absent anterosuperior } \\
\text { labrum. }\end{array}$ & $\begin{array}{l}\text { Avoid repairing anterosuperior } \\
\text { labral variants, which can over- } \\
\text { constrain the shoulder and lead } \\
\text { to stiffness. }\end{array}$ \\
\hline $\begin{array}{l}\text { When considering operative } \\
\text { management of a SLAP lesion in } \\
\text { an athlete, set realistic return-to- } \\
\text { play expectations preoperatively. }\end{array}$ & \\
\hline
\end{tabular}

intraarticular portion of the biceps tendon from the overhead athlete's shoulder.

Unfortunately, a large proportion of athletes undergoing either arthroscopic SLAP repair or BT will not RTP. This becomes increasingly worrisome with collegiate or professional athletes. Thus, it is imperative that clinicians and patients work as a team to exhaust all nonoperative therapies prior to any surgical management. A patient-centered discussion of realistic expectations should take place.

Overall, the composite RTP rate in BT appear to be in the range of $70 \%{ }^{58}$ That is compared to the RTP rates of $40-84 \%$ seen with arthroscopic SLAP repair. ${ }^{58}$ In recreational athletes, it appears that BT is a reasonable option and has been shown to have high rates of patient satisfaction and RTP. ${ }^{57}$ BT is a quick and safe procedure with relatively few complications.

\section{Disclosure}

Peter N. Chalmers is a paid consultant and speaker and receives intellectual property royalties from DePuy; and 
receives publishing royalties from the Journal of Shoulder and Elbow Surgery. Dr Peter N. Chalmers also reports grants from NIH, grants from MLB, outside the submitted work. The authors report no other conflicts of interest in this work.

\section{References}

1. Andrews JR, Carson WG, McLeod WD. Glenoid labrum tears related to the long head of the biceps. Am J Sports Med. 1985;13 (5):337-341. doi:10.1177/036354658501300508

2. Conte S, Camp CL, Dines JS. Injury trends in major league baseball over 18 seasons: 1998-2015. Am J Orthop. 2016;45(3):116-123.

3. Posner M, Cameron KL, Wolf JM, Belmont PJ, Owens BD. Epidemiology of major league baseball injuries. Am J Sports Med. 2011;39(8):1676-1680. doi:10.1177/0363546511411700

4. Kibler WB, Sciascia A. Current practice for the diagnosis of a SLAP lesion: systematic review and physician survey. Arthroscopy. 2015;31 (12):2456-2469. doi:10.1016/j.arthro.2015.06.033

5. Patterson BM, Creighton RA, Spang JT, Roberson JR, Kamath GV. Surgical trends in the treatment of superior labrum anterior and posterior lesions of the shoulder: analysis of data from the American Board of Orthopaedic Surgery certification examination database. Am J Sports Med. 2014;42(8):1904-1910. doi:10.1177/ 0363546514534939

6. Weber SC, Martin DF, Seiler JG, Harrast JJ. Superior labrum anterior and posterior lesions of the shoulder: incidence rates, complications, and outcomes as reported by American Board of Orthopedic Surgery. Part II candidates. Am J Sports Med. 2012;40(7):1538-1543. doi:10.1177/0363546512447785

7. Gorantla K, Gill C, Wright RW. The outcome of type II SLAP repair: a systematic review. Arthroscopy. 2010;26(4):537-545. doi:10.1016/ j.arthro.2009.08.017

8. Sayde WM, Cohen SB, Ciccotti MG, Dodson CC. Return to play after type II superior labral anterior-posterior lesion repairs in athletes: a systematic review. Clin Orthop Relat Res. 2012;470 (6):1595-1600. doi:10.1007/s11999-012-2295-6

9. Erickson BJ, Jain A, Abrams GD, et al. SLAP lesions: trends in treatment. Arthroscopy. 2016;32(6):976-981. doi:10.1016/j.arthro.2015.11.044

10. Werner BC, Brockmeier SF, Gwathmey FW. Trends in long head biceps tenodesis. Am J Sports Med. 2015;43(3):570-578. doi:10.1177/0363546514560155

11. Chalmers PN, Trombley R, Cip J, et al. Postoperative restoration of upper extremity motion and neuromuscular control during the overhand pitch: evaluation of tenodesis and repair for superior labral anterior-posterior tears. Am J Sports Med. 2014;42(12):2825-2836. doi:10.1177/0363546514551924

12. Dougherty MC, Kulenkamp JE, Boyajian H, Koh JL, Lee MJ, Shi LL. National trends in the diagnosis and repair of SLAP lesions in the United States. J Orthop Surg. 2020;28(1):2309499019888552. doi:10.1177/2309499019888552

13. Lesniak BP, Baraga MG, Jose J, Smith MK, Cunningham S, Kaplan LD. Glenohumeral findings on magnetic resonance imaging correlate with innings pitched in asymptomatic pitchers. Am J Sports Med. 2013;41(9):2022-2027. doi:10.1177/0363546513491093

14. Neuman BJ, Boisvert CB, Reiter B, Lawson K, Ciccotti MG, Cohen SB. Results of arthroscopic repair of type II superior labral anterior posterior lesions in overhead athletes: assessment of return to preinjury playing level and satisfaction. Am J Sports Med. 2011;39 (9):1883-1888. doi:10.1177/0363546511412317

15. Takeuchi Y, Sugaya H, Takahashi N, et al. Superior labral injuries in elite gymnasts: symptoms, pathology, and outcomes after surgical repair. Orthop J Sports Med. 2020;8(7):2325967120935001. doi:10.1177/2325967120935001
16. Gil JA, Goodman AD, DeFroda SF, Owens BD. Characteristics of operative shoulder injuries in the national collegiate athletic association, 2009-2010 through 2013-2014. Orthop J Sports Med. 2018;6 (8):2325967118790764. doi:10.1177/2325967118790764

17. Jo YH, Oh HK, Jeong SY, Lee BG. National trends in the repair of isolated superior labral tear from anterior to posterior in Korea. J Korean Med Sci. 2020;35(34):e285. doi:10.3346/jkms.2020.35.e285

18. Snyder SJ, Karzel RP, Del Pizzo W, Ferkel RD, Friedman MJ. SLAP lesions of the shoulder. Arthroscopy. 1990;6(4):274-279. doi:10.1016/0749-8063(90)90056-J

19. Maffet MW, Gartsman GM, Moseley B. Superior labrum-biceps tendon complex lesions of the shoulder. Am J Sports Med. 1995;23:93-98. doi:10.1177/036354659502300116

20. Morgan CD, Burkhart SS, Palmeri M, Gillespie M. Type II SLAP lesions: three subtypes and their relationships to superior instability and rotator cuff tears. Arthroscopy. 1998;14:553-565. doi:10.1016/ S0749-8063(98)70049-0

21. Burkhart SS, Morgan CD. The peel-back mechanism: its role in producing and extending posterior type II SLAP lesions and its effect on SLAP repair rehabilitation. Arthroscopy. 1998;14:637-640. doi:10.1016/S0749-8063(98)70065-9

22. Walch G, Boileau P, Noel E, Donell ST. Impingement of the deep surface of the supraspinatus tendon on the posterosuperior glenoid rim: an arthroscopic study. J Shoulder Elbow Surg. 1992;1 (5):238-245. doi:10.1016/S1058-2746(09)80065-7

23. Kuhn JE, Lindholm SR, Huston LJ, Soslowsky LJ, Blasier RB. Failure of the biceps superior labral complex: a cadaveric biomechanical investigation comparing the late cocking and early deceleration positions of throwing. Arthroscopy. 2003;19:373-379. doi:10.1053/ jars.2003.50044

24. Shepard MF, Dugas JR, Zeng N, Andrews JR. Differences in the ultimate strength of the biceps anchor and the generation of type II superior labral anterior posterior lesions in a cadaveric model. Am J Sports Med. 2004;32:1197-1201. doi:10.1177/0363546503262643

25. Pradhan RL, Itoi E, Hatakeyama Y, Urayama M, Sato K. Superior labral strain during the throwing motion: a cadaveric study. Am J Sports Med. 2001;29:488-492. doi:10.1177/03635465010290041801

26. Rose MB, Noonan T. Glenohumeral internal rotation deficit in throwing athletes: current perspectives. Open Access J Sports Med. 2018;9:69-78. doi:10.2147/OAJSM.S138975

27. Pandya NK, Colton A, Webner D, Sennett B, Huffman GR. Physical examination and magnetic resonance imaging in the diagnosis of superior labrum anterior-posterior lesions of the shoulder: a sensitivity analysis. Arthroscopy. 2008;24(3):311-317. doi:10.1016/j.arthro.2007.09.004

28. Meserve BB, Cleland JA, Boucher TR. A meta-analysis examining clinical test utility for assessing superior labral anterior posterior lesions. Am J Sports Med. 2009;37(11):2252-2258. doi:10.1177/ 0363546508325153

29. O’Brien SJ, Pagnani MJ, Fealy S, McGlynn SR, Wilson JB. The active compression test: a new and effective test for diagnosing labral tears and acromioclavicular joint abnormality. Am J Sports Med. 1998;26(5):610-613. doi:10.1177/03635465980260050201

30. McFarland EG, Kim TK, Savino RM. Clinical assessment of three common tests for superior labral anterior-posterior lesions. Am J Sports Med. 2002;30(6):810-815. doi:10.1177/03635465020300061001

31. Parentis MA, Glousman RE, Mohr KS, Yocum LA. An evaluation of the provocative tests for superior labral anterior posterior lesions. $\mathrm{Am}$ J Sports Med. 2006;34(2):265-268. doi:10.1177/0363546505279911

32. Myers TH, Zemanovic JR, Andrews JR. The resisted supination external rotation test: a new test for the diagnosis of superior labral anterior posterior lesions. Am J Sports Med. 2005;33(9):1315-1320. doi:10.1177/0363546504273050

33. Guanche CA, Jones DC. Clinical testing for tears of the glenoid labrum. Arthroscopy. 2003;19(5):517-523. doi:10.1053/jars.2003.50104 
34. Nakagawa S, Yoneda M, Hayashida K, Obata M, Fukushima S, Miyazaki Y. Forced shoulder abduction and elbow flexion test: a new simple clinical test to detect superior labral injury in the throwing shoulder. Arthroscopy. 2005;21(11):1290-1295. doi:10.1016/j.arthro.2005.08.025

35. Sodha S, Srikumaran U, Choi K, Borade AU, McFarland EG. Clinical assessment of the dynamic labral shear test for superior labrum anterior and posterior lesions. Am J Sports Med. 2017;45 (4):775-781. doi:10.1177/0363546517690349

36. Ben kibler W, Sciascia AD, Hester P, Dome D, Jacobs C. Clinical utility of traditional and new tests in the diagnosis of biceps tendon injuries and superior labrum anterior and posterior lesions in the shoulder. Am J Sports Med. 2009;37(9):1840-1847. doi:10.1177/ 0363546509332505

37. Clark RC, Chandler CC, Fuqua AC, Glymph KN, Lambert GC, Rigney KJ. Use of clinical test clusters versus advanced imaging studies in the management of patients with a suspected slap tear. Int J Sports Phys Ther. 2019;14(3):345-352. doi:10.26603/ ijspt20190345

38. Sheridan K, Kreulen C, Kim S, Mak W, Lewis K, Marder R. Accuracy of magnetic resonance imaging to diagnose superior labrum anterior-posterior tears. Knee Surg Sports Traumatol Arthrosc. 2015;23(9):2645-2650. doi:10.1007/s00167-014-3109-z

39. Knesek M, Skendzel JG, Dines JS, Altchek DW, Allen AA, Bedi A. Diagnosis and management of superior labral anterior posterior tears in throwing athletes. Am J Sports Med. 2013;41(2):444-460. doi: $10.1177 / 0363546512466067$

40. Arirachakaran A, Boonard M, Chaijenkij K, Pituckanotai K, Prommahachai A, Kongtharvonskul J. A systematic review and metaanalysis of diagnostic test of MRA versus MRI for detection superior labrum anterior to posterior lesions type II-VII. Skeletal Radiol. 2017;46(2):149-160. doi:10.1007/s00256-016-2525-1

41. Symanski JS, Subhas N, Babb J, Nicholson J, Gyftopoulos S. Diagnosis of superior labrum anterior-to-posterior tears by using MR imaging and MR arthrography: a systematic review and meta-analysis. Radiology. 2017;285(1):101-113. doi:10.1148/ radiol.2017162681

42. Kanatli U, Ozturk BY, Bolukbasi S. Anatomical variations of the anterosuperior labrum: prevalence and association with type II superior labrum anterior-posterior (SLAP) lesions. J Shoulder Elbow Surg. 2010;19(8):1199-1203. doi:10.1016/j.jse.2010.07.016

43. Rao AG, Kim TK, Chronopoulos E, McFarland EG. Anatomical variants in the anterosuperior aspect of the glenoid labrum: a statistical analysis of seventy-three cases. J Bone Joint Surg Am. 2003;85(4):653-659. doi:10.2106/00004623-20030400000011

44. Keener JD, Brophy RH. Superior labral tears of the shoulder: pathogenesis, evaluation, and treatment. J Am Acad Orthop Surg. 2009;17 (10):627-637. doi:10.5435/00124635-200910000-00005

45. Shin SJ, Lee J, Jeon YS, Ko YW, Kim RG. Clinical outcomes of nonoperative treatment for patients presenting SLAP lesions in diagnostic provocative tests and MR arthrography. Knee Surg Sports Traumatol Arthrosc. 2017;25(10):3296-3302. doi:10.1007/s00167016-4226-7

46. Edwards SL, Lee JA, Bell JE, et al. Nonoperative treatment of superior labrum anterior posterior tears: improvements in pain, function, and quality of life. Am J Sports Med. 2010;38(7):1456-1461. doi:10.1177/0363546510370937

47. Fedoriw WW, Ramkumar P, McCulloch PC, Lintner DM. Return to play after treatment of superior labral tears in professional baseball players. Am J Sports Med. 2014;42(5):1155-1160. doi:10.1177/ 0363546514528096

48. Kim SH, Ha KI, Kim SH, Choi HJ. Results of arthroscopic treatment of superior labral lesions. J Bone Joint Surg Am. 2002;84 (6):981-985. doi:10.2106/00004623-200206000-00012
49. Enad JG, Gaines RJ, White SM, Kurtz CA. Arthroscopic superior labrum anterior-posterior repair in military patients. J Shoulder Elbow Surg. 2007;16(3):300-305. doi:10.1016/j.jse.2006.05.015

50. Friel NA, Karas V, Slabaugh MA, Cole BJ. Outcomes of type II superior labrum, anterior to posterior (SLAP) repair: prospective evaluation at a minimum two-year follow-up. $J$ Shoulder Elbow Surg. 2010;19(6):859-867. doi:10.1016/j.jse.2010.03.004

51. Strauss EJ, Salata MJ, Sershon RA, et al. Role of the superior labrum after biceps tenodesis in glenohumeral stability. J Shoulder Elbow Surg. 2014;23:485-491. doi:10.1016/j.jse.2013.07.036

52. Patzer T, Habermeyer P, Hurschler C, et al. The influence of superior labrum anterior to posterior (SLAP) repair on restoring baseline glenohumeral translation and increased biceps loading after simulated SLAP tear and the effectiveness of SLAP repair after long head of biceps tenotomy. J Shoulder Elbow Surg. 2012;21:1580-1587. doi:10.1016/j.jse.2011.11.005

53. Kumar VP, Satku K, Balasubramaniam P. The role of the long head of biceps brachii in the stabilization of the head of the humerus. Clin Orthop Relat Res. 1989;244:172-175.

54. Giphart JE, Elser F, Dewing CB, Torry MR, Millett PJ. The long head of the biceps tendon has minimal effect on in vivo glenohumeral kinematics: a biplane fluoroscopy study. Am J Sports Med. 2012;40 (1):202-212. doi:10.1177/0363546511423629

55. Chalmers PN, Erickson BJ, Verma NN, D'Angelo J, Romeo AA. Incidence and return to play after biceps tenodesis in professional baseball players. Arthroscopy. 2018;34(3):747-751. doi:10.1016/j. arthro.2017.08.251

56. Griffin JW, Cvetanovich GL, Kim J, et al. Biceps tenodesis is a viable option for management of proximal biceps injuries in patients less than 25 years of age. Arthroscopy. 2019;35(4):1036-1041. doi:10.1016/j.arthro.2018.10.151

57. Pogorzelski J, Horan MP, Hussain ZB, Vap A, Fritz EM, Millett PJ. Subpectoral biceps tenodesis for treatment of isolated type II SLAP lesions in a young and active population. Arthroscopy. 2018;34 (2):371-376. doi:10.1016/j.arthro.2017.07.021

58. Frantz TL, Shacklett AG, Martin AS, et al. Biceps tenodesis for superior labrum anterior-posterior tear in the overhead athlete: a systematic review. Am J Sports Med. 2020;24:363546520921177.

59. Dunne KF, Knesek M, Tjong VK, et al. Arthroscopic treatment of type II superior labral anterior to posterior (SLAP) lesions in a younger population: minimum 2-year outcomes are similar between SLAP repair and biceps tenodesis. Knee Surg Sports Traumatol Arthrosc. 2021;29(1):257-265. doi:10.1007/s00167-020-05971-0

60. Abdul-Rassoul H, Defazio M, Curry EJ, Galvin JW, Li X. Return to sport after the surgical treatment of superior labrum anterior to posterior tears: a systematic review. Orthop J Sports Med. 2019;7 (5):2325967119841892.

61. Li M, Shaikh AB, Sun J, Shang P, Shang X. Effectiveness of biceps tenodesis versus SLAP repair for surgical treatment of isolated SLAP lesions: a systemic review and meta-analysis. $J$ Orthop Translat. 2018;4(16):23-32.

62. Chalmers PN, Monson B, Frank RM, et al. Combined SLAP repair and biceps tenodesis for superior labral anterior-posterior tears. Knee Surg Sports Traumatol Arthrosc. 2016;24(12):3870-3876. doi:10.1007/s00167-015-3774-6

63. Boileau P, Krishnan SG, Coste JS, Walch G. Arthroscopic biceps tenodesis: a new technique using bioabsorbable interference screw fixation. Arthroscopy. 2002;18(9):1002-1012. doi:10.1053/ jars.2002.36488

64. Mazzocca AD, Romeo AA. Arthroscopic biceps tenodesis in the beach chair position. Oper Tech Sports Med. 2003;11:6-14. doi:10.1053/otsm.2003.35895

65. Mazzocca AD, Rios CG, Romeo AA, Arciero RA. Subpectoral biceps tenodesis with interference screw fixation. Arthroscopy. 2005;21:896e1-896e7. doi:10.1016/j.arthro.2005.04.002 
66. Millett PJ, Sanders B, Gobezie R, Braun S, Warner JP. Interference screw vs. suture anchor fixation for open subpectoral biceps tenodesis: does it matter? BMC Musculoskelet Disord. 2008;9:121. doi:10.1186/1471-2474-9-121

67. Provencher MT, LeClere LE, Romeo AA. Subpectoral biceps tenodesis. Sports Med Arthrosc Rev. 2008;16:170-176. doi:10.1097/ JSA.0b013e3181824edf

68. Denard PJ, Dai X, Hanypsiak BT, Burkhart SS. Anatomy of the biceps tendon: implications for restoring physiological length-tension relation during biceps tenodesis with interference screw fixation. Arthroscopy. 2012;28:1352-1358. doi:10.1016/j. arthro.2012.04.143

69. Wolf RS, Zheng N, Weichel D. Long head biceps tenotomy versus tenodesis: a cadaveric biomechanical analysis. Arthroscopy. 2005;21:182-185. doi:10.1016/j.arthro.2004.10.014

70. Mazzocca AD, Bicos J, Santangelo S, Romeo AA, Arciero RA. The biomechanical evaluation of four fixation techniques for proximal biceps tenodesis. Arthroscopy. 2005;21:1296-1306. doi:10.1016/j. arthro.2005.08.008

71. Ozalay M, Akpinar S, Karaeminogullari O. Mechanical strength of four different biceps tenodesis techniques. Arthroscopy. 2005;21:992-998. doi:10.1016/j.arthro.2005.05.002
72. Golish SR, Caldwell PE, Miller MD. Interference screw versus suture anchor fixation for subpectoral tenodesis of the proximal biceps tendon: a cadaveric study. Arthroscopy. 2008;24:1103-1108. doi:10.1016/j.arthro.2008.05.005

73. Nho SJ, Reiff SN, Verma NN, Slabaugh MA, Mazzocca AD, Romeo AA. Complications associated with subpectoral biceps tenodesis: low rates of incidence following surgery. J Shoulder Elbow Surg. 2010;19:764-768. doi:10.1016/j.jse.2010.01.024

74. Gupta AK, Chalmers PN, Klosterman EL, et al. Subpectoral biceps tenodesis for bicipital tendonitis with SLAP tear. Orthopedics. 2015;38(1):e48-53. doi:10.3928/01477447-20150105-60

75. Griffin JW, Leroux TS, Romeo AA. Management of proximal biceps pathology in overhead athletes: what is the role of biceps tenodesis? Am J Orthop. 2017;46(1):E71-E78.

76. Deng ZJ, Yin C, Cusano J, et al. Outcomes and complications after primary arthroscopic suprapectoral versus open subpectoral biceps tenodesis for superior labral anterior-posterior tears or biceps abnormalities: a systematic review and meta-analysis. Orthop $J$ Sports Med. 2020;8(8):2325967120945322. doi:10.1177/ 2325967120945322

\section{Publish your work in this journal}

Open Access Journal of Sports Medicine is an international, peerreviewed, open access journal publishing original research, reports, reviews and commentaries on all areas of sports medicine. The manuscript management system is completely online and includes a very quick and fair peer-review system. Visit http://www.dovepress. com/testimonials.php to read real quotes from published authors. 